\title{
The Promoting Effects of Psychology in Business Negotiation
}

\author{
Qing Cheng \\ Zhejiang Ocean University, Zhoushan, China \\ Yeli Shi \\ Zhejiang Ocean University, Zhoushan, China
}

\begin{abstract}
- with the prosperity of the world economy, each country gradually converts its priority of the development to the economic growth. Economic activities such as import and export are more frequent than before. In this process, business negotiation is indispensable. On the study of business negotiation, scholars at home and abroad have put relentless efforts and have made tremendous contributions to the success of business transactions. However, in practical business negotiations, although negotiators have mastered a certain level of knowledge of business negotiation, they still encounter some problems. These problems, to some extent, can be solved by the employment of psychological knowledge. In this paper, psychological theories such as Attribution Theory, Intergroup Conflict Theory, Maslow's Hierarchy of Needs, and Foot-in-the-Door Technique are applied and analyzed to help negotiators achieve the most important goal in business negotiations.
\end{abstract}

Index Terms-business negotiation, psychology, Attribution Theory, Intergroup Conflict Theory, Maslow's Hierarchy of Needs, Foot-in-the-Door Technique

\section{INTRODUCTION}

In today's world, a country's economy is not only related to national security, territorial integrity, but also to the lives of the people. Under the background of economic globalization, economic activities are also more and more frequent, and business negotiation is essential to economic activities. Business negotiation is the negotiation for reaching an agreement between the two sides of the transaction, which will affect or even decide the content of cooperation.

Scholars at home and abroad are becoming more and more mature in the study of business negotiation, but they mainly focus on the strategy, skills, influencing factors and cultural conflicts of business negotiation. Relatively speaking, there is little research on the role of psychology in promotion and guidance of business negotiation.

As a discipline, psychology studies behavior and psychological activities. Although the business negotiation is the exchange of interests between negotiators, but to some extent, it is the inner contest between business negotiators. Business negotiators should first understand themselves. That is, they need to negotiate with themselves. In this part, Attribution Theory can demonstrate why negotiators tend to produce some emotions in business negotiations. After fully understanding their own existent emotions, negotiators may realize the multiplicity of themselves, and thus control their own emotions in real business negotiations, and prevent themselves from losing control of emotions and avoid the eventual failure of business negotiations. Besides, non-passive business negotiators know how to guide the opposite side's emotions in order to take control of business negotiations. Intergroup Conflict Theory shows that there are inevitable conflicts in business negotiations, but negotiators should still extend themselves to avoiding confrontational negotiations which will hamper the pace of win-win situation. When negotiators want to satisfy their own needs, they must take the opposite side's needs into account. In this process, negotiators will certainly keep the cost as low as possible, where the Maslow's Hierarchy of Needs functions as a guidance to find the opposite side's biggest need. Moreover, negotiators should try to form conditioned reflexes which are beneficial to business negotiations. Everything should be done step by step, so in business negotiations negotiators cannot ask for everything up front, the principle of which can be found in Foot-in-the-Door Technique. Negotiators need to first lead the opposite side to make the first decision, an agreement reached on one small request, and then they may lead their rivals to more significant agreements.

This thesis mainly discusses that the knowledge of psychology can assist negotiators in business negotiations in four ways. One is that psychology can help negotiators understand their own emotions more clearly, and then know how to control them. The second is that psychology can help business negotiators avoid confrontational negotiations and know the significance of considering the opposite side's needs. The third one is that psychology can help negotiators form conditioned reflexes which can exert great impact on improving negotiators' performance in real business negotiations. The last one is that before putting forward the important proposals negotiators should let the opposite side agree on a trivial request, an easy decision for the opposite side to make, which may pave the way for a bigger agreement. 


\section{The MultiPlicity of NegOtiators AND THE ATtRIBUtion TheORY}

In business negotiations, negotiators often meet a kind of situation that they may generate some negative emotions and even do not know why these emotions can be produced. The most severe problem is that negotiators cannot accept these emotions, because they do not believe these emotions arise from their personalities. The reason for it is that negotiators do not have a comprehensive grasp of themselves. That is, negotiators fail to realize the multiplicity of themselves. For this reason, negotiators cannot detect the adverse emotions hidden inside negotiators, still less control these emotions. However, controlling emotions is significant for negotiators, that is why negotiators need to know about the multiplicity of themselves. Psychologist Jay Early described this well when he wrote, "The human mind isn't a unitary thing that sometimes has irrational feelings. It is a complex system of interacting parts, each with a mind of its own." (Fox, 2013) Negotiators have multi-faceted, and they usually focus on the certain good sides of their personalities, but unconsciously close their eyes to those adverse sides which will result in anger, discontent, jealousy, and other bad emotions. Therefore, negotiators are supposed to fully know about themselves, understand their own emotions so that they can control their emotions in business negotiations. (Diamond, 2010) Attribution Theory, which may explain conscious or unconscious social behaviors appearing in a certain environment, is conducive to the effective control of emotions and adaption to the environment. It also gives a theoretical foundation to the existence of emotions.

The formal definition of Attribution Theory is provided by Fiske and Taylor (1991), "Attribution theory deals with how the social perceiver uses information to arrive at causal explanations for events. It examines what information is gathered and how it is combined to form a causal judgment".

In 1958, Fritz Heider proposed the Attribution Theory from the point of naive psychology. He put forward two main influential ideas: dispositional attrition (internal cause) vs. situational attribution (external cause). Dispositional attribution ascribes the behavior to some internal characteristic of a person, rather than to outside forces, which backs the idea that some unnoticed sides of negotiators will influence their behaviors. Erica Ariel Fox, a renowned international negotiator and a professor of negotiation at Harvard Law School, introduced a situation called performance gap, which was described as such what negotiators behaved in reality was not inconsistent with their thoughts. "The first step in closing the performance gap was seeing your own role in the results you were getting", (2013:87) which required negotiators to have all-sided cognition of themselves. In general, business negotiators think of themselves partially, and they generate self-cognition with those one-sided understanding. Therefore, it is necessary for negotiators to get close to true self and envisage their good sides and bad sides, which will help negotiators to find the reason of some behaviors.

For example, Giovanna (Fox, 2013) was a sales manager in a national insurance carrier, in charge of driving new business and increasing premium income in her territory. In addition, she also oversaw several teams of sales representatives. She felt awfully frustrated because of two consecutive failures to get promoted. She did not know what the problem was, for she had made stellar performance. Her sales representatives had also met their premium targets, and her agents had offered competitive price to consumers. She just accepted the first failure quietly, but the second time she decided to ask for reasons from the director of sales, who told her that her sales teams showed unwillingness to continue working for her, because she was too forceful when she was negotiating over sales targets with other team members and once she was under pressure her hostility would arise. The director of sales even cautioned her that if she did not get her management style under control, she would never be promoted. What the director of sales said shocked her, because she did not realize her bad behaviors and unreasonable request to her sales representatives. Her account of herself was a principled, hardworking, and very successful businesswoman. She just ignored that she sometimes was draconian. What she needed to do was to be aware of some neglected bad sides in herself and to improve her self-knowledge.

In this case, the negotiator's self-knowledge can exert considerable impact on the business negotiation, which not only will influence the relation between the negotiator and other members, but also is adverse to the final result achieved by the negotiation. Negotiators should understand themselves comprehensively in order to raise the level of self-knowledge. Dr. Daniel Siegel, a renowned brain researcher and professor at the university of California, Los Angeles, explains it this way in his book Mindsight, "We must accept our multiplicity, the fact that we can show up quite differently in our athletic, intellectual, sexual, spiritual or many other states. A heterogeneous collection of states is completely normal in us humans." (Fox: 105) Negotiators need to admit and accept some sides of their self-knowledge that they fail to recognize yet in order to see how they are getting in their own way. (Gerrig \& Zimbardo, 2012) The problem is not that negotiators cannot hear the feedback, but is that they will not believe it without making a change of their self-knowledge. Therefore, self-knowledge is essential to business negotiation, which facilitates negotiators' better understanding of themselves through the familiarization of the causes of their emotions and their behaviors, thus emotions will be no longer a hindrance for negotiators to successful business negotiations.

\section{The Guiding EfFects of Psychology in Business Negotiation}

In business negotiations, negotiators' performance is deservedly decisive, but because the business negotiation is the exchange and communication between negotiators and the opposite side, it should also be taken into consideration that the opposite side' psychological status and emotions. The knowledge of psychology can help negotiators guide the 
opposite side's emotions, which makes the business negotiation move toward a more favorable direction. For achieving win-win situation, negotiators should avoid confrontational negotiation. Besides, considering the opposite side's needs can arrive at the achievement of mutual benefits.

\section{A. Avoiding Confrontational Negotiation and Intergroup Conflict Theory}

As negotiators proceed into the middle stages of the negotiation and the issues become more defined, it is important for them to avoid confrontational negotiation (Dawson, 1999). In order to shun confrontational negotiating, negotiators should make every endeavor to reduce the opposite side's hostility. Hostility is extremely detrimental to business negotiations, which can make negotiations difficult to move forward in that the opposite side is easy to generate antipathy to the negotiator's proposals and lead to a rather embarrassing atmosphere or even a deadlock between the two sides. As negotiators and the opposite side stand for different parties, so it is natural and unavoidable for negotiators to be in conflict with the opposite side. The Intergroup Conflict Theory can give an elaborate and compelling explanation of the existence of conflicts between negotiators and the opposite side.

The Intergroup Conflict Theory is about the reasons, functions and solutions of intergroup conflicts. One of the reasons of intergroup conflicts is competition. The behavioral scientist that Andrew J. Dubrin, as the representative of this theory, divided conflicts into two parts from two perspectives (1978). One is beneficial and harmful, and the other is substantive and individual. Substantive conflicts are involved in hate and envy. They are rooted in personal emotions and attitude.

For instance, Winston Churchill (Dawson, 1999) was a grand old man who had a serious problem that he loved to drink. He was all the time quarreling with Lady Astor, who was in favor of liquor prohibition. One day, she came up to him and said that he was disgusting and drunken, and he should quit drinking and totally change himself. He said to her that she was absolutely right that he was a drunk, but she was ugly. And he would be sober again in the next morning.

In this case, when the two people are arguing over one subject, one chooses to agree with the other's opinion, which can make the other unable to counter immediately. In business negotiations, when the opposite side puts forward unreasonable requirements, negotiators should be composed not to make any dissent straight away, because it will cause the business negotiations to become confrontational. When disputes occur, it is instinct for the two side to argue with each other. Instead of arguing up front, which may lead to confrontational negotiation, it is advisable that negotiators get into the habit of agreeing first and then turning it around (Dawson, 1999). When the opposite side finds that his views are accepted instead of being refuted, he will naturally appreciate the business negotiator. Business negotiators agree with the opposite side's views in order to disintegrate the opposite side's psychological defense, thus facilitating their acceptance of the negotiators' views. In other words, business negotiators' approval of the opposite side is in fact a way to acquire the opposite side's approval.

\section{B. Considering the Opposite Side's Needs and Maslow's Hierarchy of Needs}

In business negotiations, both sides of the negotiation must have respective needs, and that is exactly why the business negotiations happen. (Yang, 2017) Negotiators come to business negotiations, undoubtedly, for meeting their needs. However, negotiators cannot only focus their own need, because the business negotiation is an economic activity which should be implemented by both sides. When negotiators are willing to consider the opposite side's needs, it will make the opposite side feel that negotiators are sincere to negotiate and this business negotiation is meaningful. Therefore, considering the opposite side's needs can break down the opposite side's psychological defense. What's more, consideration of the opposite side's needs does not mean that negotiators make concession. In practice, it is more unlikely that the opposite side will make concessive decision. Negotiators should find the opposite side's real need in order to prevent making excess and unnecessary losses and maximize their own benefits, which accords with the Maslow's Hierarchy of Needs.

Maslow's Hierarchy of Needs (1943) expounds five kinds of needs. They are physiological needs, safety needs, love and belonging, esteem and self-actualization. In business negotiations, negotiators should grasp the opposite side's real need, and if the need is reasonable, it is sensible for negotiators to agree to satisfy the opposite side, which can foster the fulfillment of negotiators' needs.

In 1970, an American lawyer (Fisher\& Ury \& Patton, 1991) got a chance to interview President Nasser of Egypt on the subject of the Arab-Israeli conflict. The lawyer asked Nasser what he wanted Golda Meir to do. Nasser's reply was to withdraw. The lawyer asked again, and Nasser's answer was to withdraw from every inch of Arab territory. Then the American lawyer asked incredulously whether she did so with a deal or she could get anything. Nasser replied that nothing. It was their territory, and she should promise to withdraw. The American lawyer asked what would happen to Golda Meir if tomorrow morning she appeared on Israeli radio and television, and said that on behalf of the people of Israel she hereby promised to withdraw from every inch of territory occupied in 1967: the Sinai, Gaza, the West Bank, Jerusalem, the Golan Heights, and she wanted people to know, she had no commitment of any kind from any Arab whatsoever. Nasser burst out laughing, and said she would have trouble at home. In the end, Nasser accepted a cease-fire in the war of attrition. Nasser considered Golda Meir's need, and thus he reached his goal.

This case shows us that negotiators need to take the opposite side's needs into account, if negotiators want to reach an agreement with each other. (Lu \& Qin, 2019) It is impossible for the opposite side to fulfill the negotiator's needs without getting anything from the negotiator. So negotiators have to give up something. When it is settled, negotiators 
should reckon what the real need of the opposite side is. The opposite side certainly has various needs, but what negotiators should focus on is the real need, in other words, the most important desire. When negotiators meet the opposite side's real need, the opposite side will get the most satisfaction. So the Maslow's Hierarchy of Need Theory can give negotiators instructions to find out the opposite side's real need and finally arrive at an agreement with the opposite side.

\section{The CONDitioned RefleXes of Negotiators Formed By Psychology}

The emotion of the negotiator is particularly essential, which will seriously affect the application of the negotiator's strategy and skills, and will make the whole business negotiation move to a direction that is not conducive to the negotiator. In the previous part of the thesis, the use of psychological knowledge to control the emotion of negotiator has been discussed. When the negotiator has learned how to control his emotion, the negotiator should also master how to turn the response for controlling emotion into an instinct. (McGonigal, 2012) The negotiator does not have enough time in the business negotiation to think about, and he has to respond appropriately in a very short period of time, so it is necessary for the negotiator to turn the appropriate emotion into his instinct. It is obvious for negotiators to have some instincts which are naturally produced but sometimes are not advantageous to business negotiations. Therefore, negotiators can cultivate some new and more beneficial instincts to facilitate business negotiations.

Based on the study of salivating dogs (Hock, 2009), Ivan Petrovich Pavlov (1890-1930) developed and articulated the classical conditioning theory a hundred years ago in Russia. Pavlov's physiological research mainly used the dogs as the subjects for studying the role of salivation on digestion. When Pavlov continued his research, he started to find strange and unexpected things that the dogs began to salivate before any food was put into their mouths and even before the odor of food was present. After a period of time, the dogs were salivating at times when no salivary stimulus was given to them. The reflexive action of the salivary glands was according to the dog's experience in the lab. For example, the dogs' secretion may be triggered even by the sight of vessel with which the food was given to the dogs. The reason why the dogs showed so strangely should be found in psychology. In reality, there are two kinds of reflexes. One is called unconditioned reflexes, which do not need any studying and are inherent and automatic, like salivating when food enters the mouth. The other is called conditioned reflexes, which is produced by studying, like salivating when seeing the vessel. The Pavlov's theories of classical conditioning explained a major portion of human behavior and helped to launch psychology as a true science.

By way of analogy, people can also nurture conditioned reflexes, so do negotiators. The above-mentioned part of thesis has discussed that negotiators should agree with the opposite side's viewpoints first. As negotiators' instinct may make negotiators dissent from the opposite side, it is necessary and meaningful for negotiators to train themselves to form conditioned reflexes. Negotiators should know what words are more acceptable to the opposite side. And the words should be accompanied by a movement. Negotiators can design a movement which is imperceptible and natural to make in business negotiations. Experiments on that unnoticeable movement should be made in business negotiations so as to verify whether it is workable or not. Negotiators first make this movement, and then let others speak about what they will agree on. If negotiators repeat this practice no less than twenty times, they will find an incredible result that after the repeated movement, they will be easier to agree with others. This is just one case. Negotiators can use this way to form other conditioned reflexes which favor business negotiations.

\section{Achieving Negotiators' Goals And Foot-IN-The-Door TeCHniQue}

In business negotiations, it is a herculean task for negotiators to achieve their goals. Negotiators come to business negotiations with their purposes, while the opposite side strives for accomplishing their own objectives and to some degree the opposite side may prevent negotiators from achieving goals. Negotiators can use a strategy called nibbling. That is, negotiators can make the opposite side agree on a small target, then put forward another target which is relatively more difficult to accomplish, and in this way negotiators can gradually get what they want. Nibbling is absolutely helpful for negotiators in business negotiations. First, it enables you to sweeten the deal you have made with the buyer, and second, you can use it to get the buyer to agree to things that he or she would not have agreed to earlier (Dawson, 1999). Foot-in-the-Door Technique also elaborates that once a person accepts one trivial request, in order to avoid cognitive inconsistence or leave consistent impression to others, it is more likely to accept another larger request.

Foot-in-the-Door Technique states that a small agreement can build a connection between the requester and the requested. Even if the requested may only have agreed to a trivial request, it will create a bond. After the requested have agreed, he will justify the agreement to himself. Later, the requested will feel forced to agree another request, because he needs to keep cognitive consistence with the former. So Foot-in-the-Door Technique expounds that a more important request should be followed by a trivial one, which is similar to the strategy called nibbling.

Julia (Dawson, 1999) wanted to get a great graduation gift from her father, and there were three lists: one was a five-week trip to Europe, the second was $\$ 1,200$ in spending money, and the last one a new set of luggage. She did not ask for everything together. Her first step began with the trip, and then gave her father a recommendation that spending money should be $\$ 1,200$. In the end she went up to her father and said whether he would want her to travel to Europe with a ratty and old set of luggage. If she asked for everything up front, her father might refuse the requests of luggage 
and spending money.

It is evident that the opposite side will feel uptight when he needs to make the decision at the first time. Because the opposite side could hardly be confident with his first decision, and he is under tremendous pressure to make up his mind. However, once the opposite side has finished his first decision, he will hold unswerving support to his decision and even gradually increase the approval in the decision. In conclusion, before the decision is made, the opposite side may have the feeling of resistance, but once he has decided to do it, he will support it. So negotiators need to drive the opposite side to make the first decision which helps the opposite side increase the confidence about his decision and later he will be more decisive to another decision. The first request must be trivial, which can remove the pressure of the opposite side to make a decision. Negotiators should know that the first decision, though superficially is not important to themselves or the opposite side, may determine the result of the ongoing business negotiation. Just as a Chinese idiom goes, "One ant hole may cause the collapse of a thousand-li dyke." The first insignificant decision may shatter the defensive mechanism of the opposite side and dismantle all the barricades of the negotiation.

\section{CONCLUSION}

Business negotiations are increasingly significant in economic activities. Negotiators can reinforce their bargaining power through the use of psychological knowledge. Psychology is able to help negotiators improve their self-awareness and control their emotions, can also cultivate the ability of negotiators to guide their opponents' emotions, assist negotiators to achieve win-win cooperation, and help negotiators form conditioned reflexes that are more conducive to business negotiations. Psychological theories provide negotiators a new way to achieve their goals.

Negotiators have a nature called multiplicity, but they often do not realize it. They are more liable to ignore or hide unconsciously some bad sides of their personalities. Therefore, negotiators fail to care about the existence of some adverse emotions, and then lose control of these adverse emotions. Keeping their emotions under control in business negotiations is on the premise that they need to value the multiplicity of themselves and have comprehensive grasp of themselves. Dispositional attribution, a major part of Attribution Theory, ascribes the cause of behavior to some characteristic of a person.

After negotiators can take good control of their emotions, they should put emphasis on the opposite side's psychological states and emotions. The best goal of business negotiations is to achieve win-win situation, and negotiators should avoid confrontational negotiation for this best result. When the opposite side is putting forward his dissenting viewpoints, negotiators should be composed enough not to wrangle with the opposite side. Practically, repulsion cannot foster negotiators to obtain more benefits. On the contrary, it will reinforce the opposite side's hostility. Intergroup Conflict Theory explains the conflicts between negotiators and the opposite side are prevailing in business negotiations. Nevertheless, negotiators can make efforts to weaken the conflicts.

A successful business negotiation must make the both sides meet their needs. Maslow's Hierarchy of Needs elaborates that people have different needs at different levels. Obviously, negotiators have their needs, and the opposite side also wants negotiators to meet their needs in business negotiations. Negotiators should take the opposite side' needs into consideration, and find out what is the real need of the opposite side, which can advance the business negotiations and facilitate the fulfillment of negotiators' targets.

According to Ivan Petrovich Pavlov's experiment (1890-1930), it is feasible for negotiators to form conditioned reflexes. Besides, Negotiators need to achieve their goals step by step. That is, negotiators eventually get to a big deal after a trivial agreement is reached, which is similar to Foot-in-the-Door Technique.

In conclusion, negotiators are supposed to extend themselves to improving their performance in business negotiations with the knowledge of psychology.

\section{REFERENCES}

[1] Dawson, R. (1999). Secrets of Power Negotiating for Sales People: Inside Secrets from a Master Negotiator. Wayne: The Career Press.

[2] Diamond, S. (2010). Getting More: How You Can Negotiate to Succeed in Work and Life. New York: Three Rivers Press.

[3] Dubrin, J.A. (1978). Fundamentals of Organizational Behavior. An Applied Perspective. Oxford: Pergamon Press Inc.

[4] Fisher, R. \& Ury, L. W. \& Patton, B. (1991). Getting to Yes: Negotiating Agreement without Giving In. London: Penguin Books.

[5] Fox, A. E. (2013). Winning from Within: A Break-through Method for Leading, Living, and Lasting Change. New York: Harper Business.

[6] Gerrig, J. R. \& Zimbardo, G. P. (2012). Psychology and Life. London: Pearson.

[7] Hock, R. R. (2009). Forty Studies that Changed Psychology: Exploration into the History of Psychological Research. London: Pearson.

[8] Lu, X. W. \& Qin, D. L. (2019). The Application of Language Arts in Business Negotiation. Literature Education, 1, 69-70.

[9] McGonigal, K. (2012). The Willpower Instinct: How Self-Control Works, Why It Matters, and What You Can Do To Get More of It. New York: Penguin Group.

[10] Yang, M. (2017). The Analysis of Critical Control Elements in the Business Negotiation. China International Business, 2, 153-154. 
Qing Cheng was born in Quzhou, China in 1998. She is a junior majoring in Business English in the Foreign Language College, Zhejiang Ocean University, China.

Yeli Shi was born in Zhoushan, China. She received her M.A. degree in literature and language from Zhejiang University, China. She is an associate professor in the Foreign Language College, Zhejiang Ocean University, China. Her current researches focus on English Language and Business English teaching. 